\title{
Slurry Phase Reaction of Elemental Silicon with Methanol in the Presence of Copper: Direct Synthesis of Trimethoxysilane
}

\author{
Joon Soo Han, Joo Hyun Cho, ${ }^{\dagger,}$ Mỵong Euy Lee, ${ }^{\dagger}$ and Bok Rụul Yoo ${ }^{+*}$ \\ Organosilicon Chemistry Laboratory, Korea Institute of Science and Technologl, P.O. Box 131, \\ Cheongrvang. Seoul 130-650, Korea. E-mail. brvoo'dkist.re.k \\ -Department of Chemistry, Graduate School, Ionsei University, Seoul 120-749, Korea \\ Received Wovember 25, 2008, Accepted January 19, 2009
}

\begin{abstract}
Slumy phase reaction of elemental silicon with methanol has been studied in the presence of copper using a small amount of cuprous chloride as an activator in DBT (dibenzyltoluene) at various temperatures from $200^{\circ} \mathrm{C}$ to $320^{\circ} \mathrm{C}$. Trimethoxysilane (1a) with a $\mathrm{Si}-\mathrm{H}$ unit was obtained as the major product and tetramethoxy silane (1b) as the minor product. The reaction worked well using a $0.5 \mathrm{wt} \% \mathrm{CuCl}$ as an activator. The optimum temperature for this direct synthesis of 1 a was $240^{\circ} \mathrm{C}$. Methosysilanes were obtained in $95 \%$ vield with $81 \%$ selectivity to 1 a from $85 \%$ conversion of elemental silicon.
\end{abstract}

Key Words: Copper. Silicon. Methanol. Trimethoxy̦silane, Alkosysilane

\section{Introduction}

Hydrosilanes with Si-H unit have been widely used as starting materials ${ }^{1 \cdot 4}$ for synthesizing organosilicon compounds through hydrosilylation with olefin in academic and industrial fields since it was discovered by J. L. Speier in $1957^{2}$ that a hexachloroplatinic acid in $i$-propyl alcohol was a very effective catalyst for hydrosilylation. ${ }^{3.4}$ Even though hydrochlorosilanes has a long sytnthetic history and been well-established in academic and industrial filed. they reacts easily with moisture to give off hydrogen chloride which is toxic for living system and nustic for iron devices. Generally organoalkoxysilanes are widely used as especially coupling agents in industrially application forms ${ }^{6}$ instead of organochlorosilanes. So an alkoxylation process for the conversion of organochlorosilanes to organpalkoxysilanes is required. Especially hydroalkoxysilanes are useful starting materials for the safe preparation of alkylalkoxysilanes with an epoxy unit. which are widely used as molding compounds in electronic industry. without a opening of eposy-ring from the hydrosilylation reaction of trialkoxysilanes with epoxylated olefin such as allyl glycidyl ether and 4-vinyl-cyclohexyl epoxide. Therefore. much attention has been paid to the development of the direct synthesis for trialkoxy silanes with Si-H unit. ${ }^{9.11}$ There were some reports for the direct synthesis of alkoxysilanes with a Si-H starting from elemental silicon with methanol in the presence of copper compounds such as $\mathrm{CuCl}^{9,11} \mathrm{CuCl}_{-}{ }^{10} \mathrm{Cu}_{\Sigma} \mathrm{O}{ }^{9}$ Such $\mathrm{Cu}$-compounds reacted easily with elemental silicon in a sintering step to give $\mathrm{Cu}_{3} \mathrm{Si}$ phase. " which is known to be an active site. ${ }^{13.16}$ but eliminating undesirable compounds tetrachlorosilane formed from the reaction of elemental silicon with copper[I. II] chlorides, ${ }^{9,1]}$ and siloxanes from that with $\mathrm{Cu}_{2} \mathrm{O}$. respectively. In a large scale production. loss of elemental silicon through undesirable reaction is worth nothing. Thus wehave studied a direct reaction of elemental silicon with methanol in the presence of copper metal using a small amount of copper compound as an activator.
We have previously reported the direct synthesis of hydrosilanes from the direct reaction of elemental silicon with a nuixture of hydrogen chloride and activated organic chlorides such as $i$-propyl chloride. ${ }^{13}$ dichloromethane, ${ }^{14}$ and chloroform ${ }^{15}$ to give Si-H containing $i$-propyltrichlorosilane. bis(chlorosilyl)methanes. and tris(clilorosilyl)methanes. respectively. ${ }^{16}$ This success in the direct synthesis of new $\mathrm{Si}-\mathrm{H}$ containing organochlorosilanes prompted us to apply to the direct reaction of elemental silicon with methanol giving methoxysilanes. trimethoxysilane with a Si-H unit (1a) and tetramethosysilane (1b). In this reaction, conversion of elemental silicon and selectivity to 1a are important factors in a high yield production.

We wish to report the results obtained from the slurry phase reaction of elemental silicon with methanol in the presence of copper using a small amount of copper chloride as an activator in a stirred reactor at temperatures between $200^{\circ} \mathrm{C}$ and $320^{\circ} \mathrm{C}$.

\section{Results and Discussion}

Reaction was carried out by feeding methanol into a slurry phase of a contact mixture of elemental silicon with $\mathrm{Cu}$. prepared by preheating using a small anount of $\mathrm{CuCl}$ as an activator under a $\mathrm{N}_{2}$ stream in a stirring-bed reactor of $330^{\circ} \mathrm{C}$ for $2 \mathrm{~h}$ in DBT (dibenzyltoluene). Reaction mixtures were collected and distilled to give methoxysilanes $\mathbf{1 a}$ and $\mathbf{1 b}$ (eq 1). The composition of methosysilanes was deternined by GLC comparing with authentic samples $1 \mathrm{a}$ and $\mathbf{1 b}$. The optimum conditions such as reaction temperature. a feeding rate of methanol, and activator for direct synthesis of trimethoxysilane starting from elemental silicon and methanol were studied in details.

$$
\mathrm{Si}+\mathrm{CH}_{3} \mathrm{OH} \stackrel{\mathrm{Cu}}{\longrightarrow} \mathrm{HSi}\left(\mathrm{OCH}_{3}\right)_{3}-\mathrm{Si}\left(\mathrm{OCH}_{3}\right)_{4}
$$

1 a

$1 b$

Effect of Reaction Temperature. Effect of reaction tem- 
Table 1. Reaction Temperature Effect on Direct Synthesis of $1 a^{a}$

\begin{tabular}{|c|c|c|c|c|c|c|c|}
\hline \multirow{3}{*}{ entry } & \multirow{3}{*}{$\begin{array}{l}\text { reaction temp. } \\
\text { ("C) }\end{array}$} & \multicolumn{4}{|c|}{ reaction mixture } & \multirow{3}{*}{ yield $(\%)^{r}$} & \multirow{3}{*}{ selectivity to $1 a^{d}$} \\
\hline & & \multirow{2}{*}{$\stackrel{g}{g}$} & \multicolumn{3}{|c|}{ percentage $(\mathrm{mmol})^{b}$} & & \\
\hline & & & $\mathrm{MeOH}$ & 1a & $1 \mathrm{~b}$ & & \\
\hline 1 & 200 & 44.7 & 15 & $73(267)$ & $9(26)$ & 73 & 91 \\
\hline 2 & 240 & 48.1 & 0.3 & $79(311)$ & $16(51)$ & 92 & 86 \\
\hline 3 & 280 & 48.1 & - & $71(280)$ & $25(79)$ & 93 & 80 \\
\hline 4 & 320 & 49.0 & - & $63(253)$ & $31(100)$ & 94 & 72 \\
\hline
\end{tabular}

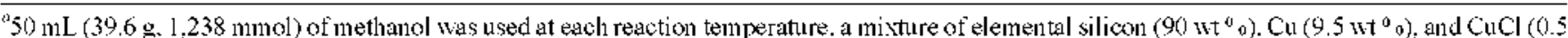

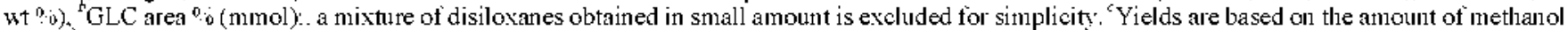
used. "Selectivity to 1a: 1asum of 1a and 1 b.

Table 2. Effect of Feeding Rate of Methanol on Direct Synthesis of $\mathbf{1}^{\sigma}$

\begin{tabular}{|c|c|c|c|c|c|c|c|}
\hline \multirow{2}{*}{ entry } & \multirow{2}{*}{$\frac{\mathrm{MeOH}}{(\mathrm{mL} / \mathrm{min})}$} & \multirow{2}{*}{$\begin{array}{c}\text { reaction } \\
\text { mixture }(\mathrm{g})\end{array}$} & \multicolumn{3}{|c|}{ percentage $(\mathrm{mmol})^{h}$} & \multirow{2}{*}{$\begin{array}{l}\text { yield' } \\
(\%)\end{array}$} & \multirow{2}{*}{$\begin{array}{c}\text { selectivity } \\
(\%)\end{array}$} \\
\hline & & & $\mathrm{MeOH}$ & $\mathrm{HSi}\left(\mathrm{OMe}_{3}\right.$ & $\mathrm{Si}(\mathrm{OMe})_{4}$ & & \\
\hline 5 & 0.25 & 48.2 & - & $79(312)$ & $16(51)$ & 92 & 86 \\
\hline 2 & 0.5 & 48.1 & 0.3 & $79(311)$ & $16(51)$ & 92 & 86 \\
\hline 6 & 1.0 & 46.0 & 13 & $73(275)$ & $10(30)$ & 76 & 90 \\
\hline
\end{tabular}

${ }^{0} 50 \mathrm{~mL}(39.6 \mathrm{~g} .1 .238 \mathrm{mmol})$ of methanol was added at $240^{\circ} \mathrm{C}$ by varying feeding rate a mixture of elemental silicon $\left(90 \mathrm{nt}{ }^{0} .0\right) . \mathrm{Cu}(9.5 \mathrm{nt} 0.6)$, and CuCl $(0.5 \mathrm{ut}: \mathrm{i})$. ${ }^{\mathrm{GLC}}$ area percentage (mol); a misture of disiloxane obtained in small amount is excluded for simplicity. "Yield is based on methanol used. 1asum of $1 \mathrm{a}$ and $1 \mathbf{b}$.

perature on the reaction of elemental silicon with methanol was studied at temperatures ranged from 200 to $320^{\circ} \mathrm{C}$. Reaction mixture, collected from each reaction at various reaction temperatures and fractional distilled to give methoxysilanes $1 \mathrm{a}$ and $\mathbf{1 b}$. In addition to methoxysilanes, disiloxane compounds were formed in a small amount. Disiloxanes can be formed by the hydroly'sis reaction of methoxysilanes with water formed by decomposition of methanol. The results are summarized in Table 1.

As shown in Table 1. total amount of reaction mixture increased from $44.7 \mathrm{~g}$ to $49.0 \mathrm{~g}$ as reaction temperature increased from $200^{\circ} \mathrm{C}$ to $320^{\circ} \mathrm{C}$. The sum yield of methosysilanes $1 \mathrm{a}$ and $\mathbf{1 b}$ based on methanol used increased from $73 \%$ to $94 \%$ as reaction temperature increased from $200^{\circ} \mathrm{C}$ to 320 ${ }^{\circ} \mathrm{C}$ suggesting that reactivity of elemental silicon with methanol increases. The selectivity to 1 a decreased from $91 \%$ at $200^{\circ} \mathrm{C}$ to $86 \%$ at $240{ }^{\circ} \mathrm{C}, 80 \%$ at $280{ }^{\circ} \mathrm{C}, 72 \%$ at $320{ }^{\circ} \mathrm{C}$ while amount of unreacted methanol recovered was decreased from $15 \%$ at $200{ }^{\circ} \mathrm{C}$ to $0.3 \%$ at $240^{\circ} \mathrm{C}$. then disappeared at $280^{\circ} \mathrm{C}$ above. The results suggest that $1 \mathrm{a}$ is formed at an early stage of this reaction and then converted to $\mathbf{1 b}$ through a dehydrogenative methosylation of 1 a with methanol. The yield of 1 a was the best at $240^{\circ} \mathrm{C}$ and decreased at temperatures below or above $240^{\circ} \mathrm{C}$. while the sum yield of $1 \mathrm{~b}$ and $\mathbf{1 b}$, increased as reaction temperature increases.

It is interesting to note that the selectivity to 1a was the lighest at $200^{\circ} \mathrm{C}$ and decreased at the temperatures above. probably due to conversion of 1a to $1 \mathrm{~b}$ through dehydrogenative methoxylation of 1 a with methanol.

Feeding Rate of Methanol. In order to optimize the rate of feeding of methanol for synthesizing methoxysilane 1a. the direct synthesis of 1 a was carried out at $240^{\circ} \mathrm{C}$ by varying feeding rate from $0.25 \mathrm{~mL} / \mathrm{min}$ to $1.0 \mathrm{~mL} / \mathrm{min}$. The results obtained from the reaction are summarized in Table 2 .

As shown in Table 2, as the feeding rate of methanol increased from $0.25 \mathrm{~mL} /$ nuin to $1.0 \mathrm{~mL} / \mathrm{nin}$, antount of methanol recovered increased from 0 at a feeding rate of 0.25 $\mathrm{mL} / \mathrm{min}$ to $13 \%$ at $1.0 \mathrm{~mL} / \mathrm{min}$. while total amount of reaction mixture decreased slightly from $48.0 \mathrm{~g}$ to $46.0 \mathrm{~g}$. The sum y ield of meththoxysilanes 1a and 1b based on methanol used generally decreased from $92 \%$ to $76 \%$ while selectivity to 1 a increased from $86 \%$ to $90 \%$ as the feeding rate of methanol increased from 0.25 (or 0.5 ) $\mathrm{mL} / \mathrm{min}$ to $1.0 \mathrm{~mL} / \mathrm{min}$. But the results obtained from a reaction with methanol at a feeding rate of $0.25 \mathrm{~mL} / \mathrm{nin}$ were similar to those from that of 1.0 $\mathrm{mL} / \mathrm{muin}$, suggesting that the optimum feeding rate of methanol in the direct sytnthesis of $1 \mathrm{a}$ was $0.5 \mathrm{~mL} / \mathrm{min}$ in viewpoint of economical production.

Effect of $\mathrm{CuCl}$ as Activator: In order to reduce the loss of elemental silicon in sintering step of silicon with copper for preparing $\mathrm{Cu}_{3} \mathrm{Si}$ phase forming undesired products such as tetrachlorosilane or disiloxanes when $\mathrm{Cu}$-compounds such as $\mathrm{CuCl}_{3}{ }^{9,11} \mathrm{CuCl}_{2}{ }^{1 / 1} \mathrm{Cu}_{2} \mathrm{O} .{ }^{9}$ etc. were used as catalyst in the direct synthesis of trimethoxysilane. Cuprous chloride. which is known as a best catalyst. gives relatively lots of tetraclulorosilane in a sintering reaction with elemental silicon. In a large scale production, loss of elemental silicon from undesirable reaction is worth nothing. Thus a directreaction of elemental silicon with methanol in the presence of copper was carried out using a small amount of $\mathrm{CuCl}$ activator ranging from $0.25 \mathrm{wt} \%$ to $1.0 \mathrm{wt} \%$ based on total solid materials. The reaction worked well with a 0.5 wt $\% \mathrm{CuCl}$ (entry no. 2) and above. The reaction of elemental silicon with methanol in the presence of copper $(4.5 \mathrm{wt} \%)$ using $\mathrm{CuCl}(\mathrm{l} .0 \mathrm{wt} \%)$ as an activator was carried out under the same reaction conditions of entry no. 2 . The results were similar to those obtained from the reaction with a 
$0.5 \mathrm{wt} \% \mathrm{CuCl}$ (entry no. 2). But a reaction using 0.25 wt $\%$ $\mathrm{CuCl}$ under the same reaction conditions of entry no. 2 showed that unreacted methanol was recovered (30\%) and activity decreased slowly according to a reaction procedure. Considering that tetrachlorosilane is produced from the sintering of silicon and copper metal using a copper chloride. hydrogen chloride might be used as an activator in a sintering step. When $\mathrm{HCl}$ was used as an activator in place of $\mathrm{CuCl}$. the direct reaction worked well. Although this reaction generally proceeds in good yields. but a little low of selectivity to 1a. it was not preferable to the reaction with $\mathrm{CuCl}$ activator because extra $\mathrm{HCl}$-controlling facility is needed.

In the direct synthesis of 1a purge of nitrogen gas helps 1a escape safely out of reactor without decomposition of 1a. Based on yield and selectivity of las the purging rate of nitrogen gas into reactor was good about $200 \mathrm{~mL} / \mathrm{min}$.

Preparation of 1a. When a large scale reaction of elemental silicon $(285 \mathrm{~g})$ with methanol $(1.110 \mathrm{~mL})$ was carried out for $37 \mathrm{~h} .85 \%$ consumption of elemental silicon gave product mixture $(991.0 \mathrm{~g})$ consisting of $1 \mathrm{a}(787 \mathrm{~g}, 6.4 \mathrm{~mol})$ and $\mathbf{1 b}$ $(27+.0 \mathrm{~g} .1 .80 \mathrm{~mol})$. In order to check if a continuous reaction is possible. when new elemental silicon $(240 \mathrm{~g})$ was charged into the reactor above when about $85 \%$ of elemental silicon was consumed the deactivation occurred. Thus once additional 0.5 wt $\% \mathrm{CuCl}$ was added into the reactor: the reaction proceeded well again. but gave $60 \%$ selectivity to 1a under the same conditions above, suggesting that $\mathrm{CuCl}$ was a useful activator for the direct synthesis of 1a, but the selectivity to 1a in a continuous process.

The optimum temperature of $240^{\circ} \mathrm{C}$ in our system was slightly lower than that in other system.

It is interesting to note that the selectivity to la was the highest at $200{ }^{\circ} \mathrm{C}$ and decreased at the temperatures above. probably due conversion of 1a to $1 \mathrm{~b}$ through dehỵdrogenative methoxylation of 1 a with methanol.

\section{Conclusions}

Slurry phase reaction of elemental silicon with methanol has been studied in the presence of copper using a small amount of $\mathrm{CuCl}$ as an activator in DBT (dibenzyltoluene) medium at $240^{\circ} \mathrm{C}$ gave trimethoxysilane in good yield. The optimum reaction temperature is $240^{\circ} \mathrm{C}$. The reaction worked well using a small amount of $\mathrm{CuCl}$ as an activator. The $\mathrm{CuCl}$ was a good activity enough for the synthesis of 1a even though 0.5 wt $\% \mathrm{CuCl}$ was used. Methoxy silanes 1a,b were obtained in $96 \%$ yield with $81 \%$ selectivity to 1 a from $85 \%$ conversion of elemental silicon

\section{Experimental Section}

Reagents and Physical Measurements. Anhydrous methanol $(99.99 \%)$ was purchased from Solkatronic chemicals and used without further purification. Copper powder was purchased from Alcan Metal Powders (NJ. USA). Elemental silicon ( $\mathrm{Si}$. 98\%: Fe. 0.50\%; Ca, 0.25\%: Al. 0.24\%, C, 0.08\%. S. $0.05 \%$. P. $0.05 \%$ ) was purchased from Samchuck Mining Co. (Kangwondo. Korea) or OSL-5-4855 (Si. 99.1\%: Al.
$0.29 \%$, Ca, $0.037 \%$. Fe, 0.30\%. Ti. 0.035\%) from Elkem Silicon (Oslo. Norway). The reaction products were analyzed by GLC using a packed column ( $10 \%$ SE-30 or SE-54 on $80-100$ mesh chromosorb W/AW. $1 / 8$ in. $\times 1.5 \mathrm{~m}$ ) or a capillary column (SE-30.30 m) with a Varian 3300 gas chromatograph. thermal conductivity detector, and Hitachi D-2500 integrator. Product yields were determined chromatographically with $n$-dodecane as an internal standard. if not described in details. Samples for characterization were purified by preparative GLC using a Donam system series DS 6200 gas chromatograph. thermal conductivity detector and a $4 \mathrm{~m} 1 / 8 \mathrm{in}$. stainless steel column packed with $20 \%$ OV-10I on $80-100$ mesh chromosorb P/AW. NMR spectra were recorded on a Varian Unity Plus 600 (FT, $600 \mathrm{MHz},{ }^{\mathrm{H}} \mathrm{H}$ ). Bruker AMX 500 (FT, $500 \mathrm{MHz},{ }^{1} \mathrm{H} ; 125 \mathrm{MHz},{ }^{13} \mathrm{C}$ ), or a Varian Gem 300 (FT, $300 \mathrm{MHz},{ }^{1} \mathrm{H} ; 75 \mathrm{MHz} .{ }^{12} \mathrm{C}$ ) spectrometer in $\mathrm{CDCl}_{\text {s }}$ solvent. Mass spectra were obtained using a Hewlett-Packard 6890 $\mathrm{GC} / \mathrm{MS}$.

Reactol: The reactor was made of a $1.8 \mathrm{~L}$ plate bottomed Pyrex glass. $11 \mathrm{~cm}$ inner dianteter and $19 \mathrm{~cm}$ length, with a 4 necked glass cover. and equipped with a mechanical stirrer withthe four blade axial impeller through a center neck and with a condenser connecting a receiver cooled by ethylene glycol at $-15^{\circ} \mathrm{C}$. Reaction temperature was measured with a thermocouple (type $\mathrm{K}$ ) which was placed inside through a hole at the glass cover. The flow rate of $\mathrm{N}_{2}$ gas was controlled by a Matheson 603 flow meter.

General Procedure for Preparation of the Contact Mixture of Elemental Silicon with Copper Using $\mathrm{CuCl}$. A mixture of metallic silicon (100-325 mesh. $285.0 \mathrm{~g})$, copper metal (13.5 g). copper(I) chloride ( $1.5 \mathrm{~g}$ ). and DBT ( $600 \mathrm{~g}$ ) was placed in the reactor. A nuixture was sintered at $330^{\circ} \mathrm{C}$ for $2 \mathrm{~h}$ with stirring under dry nitrogen flush at a rate of $200 \mathrm{~mL} / \mathrm{min}$. Some volatiles. mainly tetrachlorosilane. were formed at an early stage of sinteringprocess

The contact mixtures prepared by this procedure were used in all reactions except for study on "effect of activator for preparation of contact mixture of silicon with copper" below.

Study on the Effect of Reaction Temperature on the Direct Synthesis of 1a Direct synthesis of 1a was carried out by adding methanol into a contact mixture $(300 \mathrm{~g})$ in DBT $(600$ g) in a rate of $0.5 \mathrm{~mL} / \mathrm{min}$ at various temperatures between $200^{\circ} \mathrm{C}$ and $320^{\circ} \mathrm{C}$ in a temperature interval of $40^{\circ} \mathrm{C}$. At same time, dry nitrogen gas introduced at a rate of $200 \mathrm{~mL} / \mathrm{nuin}$. methanol was used at each reaction temperature. The results are summarized in Table 1 .

Optimization for Feeding Rate of Methanol in the Direct Synthesis of 1a. Direct reaction was carried out by adding 50 $\mathrm{mL}$ methanol into a contact nixture $(300 \mathrm{~g}) \mathrm{in} \mathrm{DBT}(600 \mathrm{~g})$ at $240^{\circ} \mathrm{C}$ at different feeding rate of methanol ranging from 0.25 to $1.0 \mathrm{~mL} / \mathrm{nin}$ at a rate of $200 \mathrm{~nL} /$ nuin under dry nitrogen flush. The results are summarized in Table 2.

Effect of $\mathrm{CuCl}$ Activatorin Preparation of Contact Mixture of Silicon with Copper. Using the same procedure described in "general procedure for preparation of the contact mixture of elemental silicon with copper using $\mathrm{CuCl}^{\prime}$ the contact mixtures were prepared using three different amounts of $\mathrm{CuCl}(0.25$. 0.5 . and $1.0 \mathrm{wt} \%$ based on solid reactants). The each contact 
mixture was tested by reaction with $50 \mathrm{~mL}$ methanol at a rate of $0.5 \mathrm{~mL} / \mathrm{min}$ at $240^{\circ} \mathrm{C}$ under the same conditions above. The reaction worked well with a $0.5 \mathrm{wt} \% \mathrm{CuCl}$ (entry no. 2) and above. The reaction of elemental silicon with methanol in the presence of copper $(4.5 \mathrm{wt} \%)$ using $\mathrm{CuCl}(1.0 \mathrm{wt} \%)$ as an activator gave similar results obtained from the reaction with a $0.5 \mathrm{wt} \% \mathrm{CuCl}$ (entry no. 2). But a reaction using $0.25 \mathrm{wt} \%$ $\mathrm{CuCl}$ showed that uneacted methanol was recovered (30\%) and activity decreased slowly as a reaction proceeded.

When $500 \mathrm{~mL}$ of gaseous hyydrogen chloride was used as an activator instead of $\mathrm{CuCl}$ in a sintering step of contact mixture. The reaction proceeded well. but selectivity to 1a was a little low $(74 \%)$ compare to the results obtained from the reaction with $\mathrm{CuCl}$ activator.

General Procedure for the Dinect Synthesis of 1a Into a 300 $\mathrm{g}$ contact mixture of silicon with copper was fed methanol at a rate of $0.5 \mathrm{~mL} / \mathrm{h}$ using a metric pump at $240^{\circ} \mathrm{C}$. At the same time nitrogen gas was introduced at a rate of $200 \mathrm{~mL} / \mathrm{min}$. About 2 min after starting the reaction. it was observed that the reaction temperature was raised slightly due to the exothermic nature of the reaction and then the liquid product was collected at the receiver. After a $37 \mathrm{~h}$ of reaction. $991.0 \mathrm{~g}$ of the product mixture was collected in receiver cooled to -15 ${ }^{\circ} \mathrm{C}$. The mixture was fractional distilled to give $1 \mathrm{a}(787 \mathrm{~g} .6 .4$ mol) and $1 \mathrm{~b}(274.0 \mathrm{~g} .1 .80 \mathrm{~mol})$. In addition to methosysilanes. $37 \mathrm{~g}$ of high boilers consisted of 1.1 .3 .3 -tetramethoxydisioloxane (26\%). pentamethoxydisiloxane (61\%), hexamethoxydisiloxane $(6 \%)$, and etc were obtained.

For a continuous reaction. after about $85 \%$ of elemental silicon was consumed under the same reaction conditions above. the temperature cooled down to room temperature with no feeding of methanol and new elemental silicon ( 240 g) and $0.5 \mathrm{wt} \% \mathrm{CuCl}(\mathrm{l} .5 \mathrm{~g})$ was charged into the reactor. sintered at $330^{\circ} \mathrm{C}$ for $2 \mathrm{~h}$. Then a reaction was carried out by the same procedure of direct synthesis of la above. The reaction proceeded well again but selectivity to 1awent down $60 \%$ wt $\%$ and production of disiloxanes mixture was increased to $30 \mathrm{wt} \%$.
Aclonowledgments. This research was supported by a grant from the Fundamental R\&D Program for Core Technology of Materials funded by the Ministry of Knowledge Economy and partially by Korea Institute of Science and Technology.

\section{Refeiences}

1. Marciniec, B. Comprehensive Handbookon Hydrositylation Pergamon Press: Oxford, 1992

2. Speier, J. L.; Webster, T. A.; Bames, G. H. J. Am. Chem. Soc. 1957, 79, 974.

3. Speier, I. L. Homogeneons Catalusis of Hydrosilation by Transition lletals in Adrances Organometallic Chemistr: Stone, F. G. A., West, R., Eds.; Academic Press: 1979; Vol. 17, $\mathrm{p} 407$.

4. Benkeser, R. A. Kang, J. J. Organomet. Chem. 1980, 185, C9.

5. (a) Combes, C. Compt. Rendus Acad. Sci. 1896, 122, 531. (b) Ruff, O.: Albert, K. Chem. Ber: 1905, 38, 2222

6. Ove, H. A.; Rong, H. M; Nygaard L ; Schussler, G.; Tuset, J. K. Silicon for the Chentical Ind stry II; Geiranger, Ed.; Nonwegian University of Science and Technology: Norway, 1998.

7. (a) Lee, S.-I.; Kim, D.-B.; Sin, J.-H.; Lee, Y.-S.: Nah, C. J. Ind. Eng. Chem. 2007, 13, 786 (b) Hong, C. K.; Hwang, I.; Kim, N.; Park, D. H.; Hwang, B. S.; Nah, C. J. Ind. Eng. Chem. 2008, 1 . 71. (c) Kim, D.; Lee, H. G.; Jung, H.; Kang, S. H. Bull. Korean Chem. Soc: $2007,26,241$

8. Crivello, I. V.: Bi, D. J. Pohm Sci., Pant .t 1993, 31,3121.

9. Peng, Z.-y.: Lan, Z.-1.; Yin, D.-1. Jingxi Shivon Huagong 2006 , 23, 54: Chem. Abstr. 2004, $1+2,76503$.

10. Suzuki, E.; Kamata, T:- Ono, Y. J. Catalysis 1990, 125, 390.

11. Suzuki, E.; Ono, Y. Shokubai 1989, 31(2), 104; Chem. Abstr:1989, 111, 115314 .

12. Mattern, N.; Seyrich, R.: Wilde, L.; Baehtz, C.; Knapp, M.; Acker, I. J. Allows Compd 2007, 429.211

13. Lim, W. C; Cho, T. H; Han, J. S.; Yoo, B. R. Bull. Korean Chem. Soc: $2007,28(10), 1661$

14. Yeon, S. H.: Han, J. S.: Yoo, B. R.: Jung, I. N. J. Organomet. Chem. 1996, 516,91.

15. Han, J. S.; Yeon, S. H.: Yoo, B. R.; Jung. I. N. Organometallics 1997, 16, 93

16. Yoo, B. R.; Jung. I. N. Adw. Organontet. Chent 2004, 50, 145 